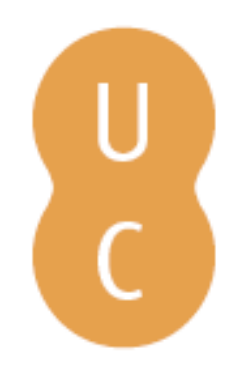

\title{
pombalina
}

\section{El arte de mantenerse joven: bibliotecas históricas de fondo antiguo}

\author{
Autor(es): Becedas-González, Margarita \\ Publicado por: Imprensa da Universidade de Coimbra \\ URL \\ persistente: URI:http://hdl.handle.net/10316.2/36975 \\ DOI: $\quad$ DOI:http://dx.doi.org/10.14195/978-989-26-1045-0_4
}

Accessed : $\quad$ 26-Apr-2023 16:24:05

A navegação consulta e descarregamento dos títulos inseridos nas Bibliotecas Digitais UC Digitalis, UC Pombalina e UC Impactum, pressupõem a aceitação plena e sem reservas dos Termos e Condições de Uso destas Bibliotecas Digitais, disponíveis em https://digitalis.uc.pt/pt-pt/termos.

Conforme exposto nos referidos Termos e Condições de Uso, o descarregamento de títulos de acesso restrito requer uma licença válida de autorização devendo o utilizador aceder ao(s) documento(s) a partir de um endereço de IP da instituição detentora da supramencionada licença.

Ao utilizador é apenas permitido o descarregamento para uso pessoal, pelo que o emprego do(s) título(s) descarregado(s) para outro fim, designadamente comercial, carece de autorização do respetivo autor ou editor da obra.

Na medida em que todas as obras da UC Digitalis se encontram protegidas pelo Código do Direito de Autor e Direitos Conexos e demais legislação aplicável, toda a cópia, parcial ou total, deste documento, nos casos em que é legalmente admitida, deverá conter ou fazer-se acompanhar por este aviso.

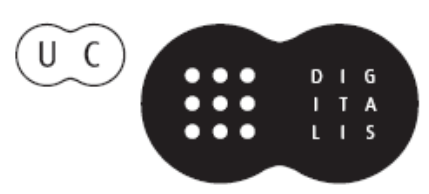



Tendo como pano de fundo as Comemorações dos seus 500 anos, a Biblioteca Geral da Universidade de Coimbra organizou um Congresso Internacional subordinado ao tema "A Biblioteca da Universidade: permanência e metamorfoses", que teve lugar nos dias 16, 17 e 18 de janeiro de 2014, no auditório da Reitoria da Universidade de Coimbra.

O objetivo maior desta reunião científica foi o de refletir sobre o presente e o futuro das bibliotecas que servem públicos universitários. Numa outra vertente, procurou chamar-se a atenção para a importância de que a Biblioteca se reveste, tendo em vista o progresso do conhecimento técnico e científico. Por último, o Congresso pretendeu instituir-se como oportunidade de reflexão prospetiva e como lugar de encontro entre as sensibilidades de todos os que trabalham profissionalmente com livros e com outros suportes de natureza bibliográfica.

Nesse sentido, foram apresentadas Conferências, Mesas Redondas e sessões de Testemunhos em torno de temas como o valor das bibliotecas universitárias, a biblioteca universitária em contexto; as mudanças e os desafios; a biblioteca universitária e a sociedade da informação e conhecimento; o impacto do acesso aberto na comunidade científica, e as bibliotecas digitais. 
MARGARITA BECEDAS-GONZÁLEZ

Universidade de Salamanca

University of Salamanca

\title{
EL ARTE DE MANTENERSE JOVEN:
}

\section{BIBLIOTECAS HISTÓRICAS DE FONDO ANTIGUO}

\author{
THE ART OF STAYING YOUNG: HISTORIC LIBRARIES
}

ReSumo: Al menos en España, las bibliotecas históricas con manuscritos e impresos antiguos fueron las grandes olvidadas durante el proceso de crecimiento de las bibliotecas en la segunda mitad de la década de los 80 y parte de los 90 . Fue un periodo de ampliación de personal bibliotecario en bibliotecas públicas y universitarias, de reorganización y, desde luego, de desarrollo tecnológico, aunque enfocado fundamentalmente hacia servicios y usuarios de fondos modernos.

El panorama ha cambiado desde finales de los 90, gracias, por una parte, a la puesta en práctica de la Ley de patrimonio y a un cierto ambiente de preocupación institucional y social por el patrimonio histórico en general; y por otra parte, al cambio de actitud de los bibliotecarios de fondo antiguo, que han renovado su gestión interna, aprovechan al máximo los recursos tecnológicos y se han abierto de forma decidida hacia la cooperación nacional e internacional. Mantener jóvenes a libros que nacieron hace siglos y evitar que las bibliotecas históricas se conviertan en organismos decadentes sin perder su idiosincrasia de instituciones venerables y clásicas, son los retos a los que se enfrentan en la actualidad los bibliotecarios de fondo antiguo. Intentando conjugar Conservación y Difusión, las bibliotecas históricas buscan ahora nuevos usuarios y han multiplicado el acceso a fondos bibliográficos que hasta hace poco tiempo estaban encerrados dentro de infranqueables muros. Esta comunicación expone la actualidad de las bibliotecas con fondos antiguos en el ámbito universitario y la transformación experimentada en los últimos años, así como el papel que tienen reservado en un futuro no muy lejano.

En el marco de este congreso sobre permanencia y metamorfosis de las bibliotecas universitarias, mi comunicación va a tratar sobre las bibliotecas de fondos antiguos en el ámbito universitario:

- De la renovación que han experimentado en los últimos años.

- De la situación actual.

- Del papel que tienen reservado en un futuro no muy lejano.

Abstract: In the case of Spain, at least, historic libraries housing manuscripts and old books were largely forgotten during the phase of library expansion in the second 
half of the 1980s and part of the 1990s. It was a period of public and university library staff increases, reorganisation and, naturally, technological development, although this focussed mainly on the relationship between users and modern resources.

The scenario changed at the end of the 1990s due, on the one hand, to the implementation of the law on heritage and a certain atmosphere of institutional and social concern for historical heritage in general and, on the other hand, to changing attitudes amongst librarians working with antiquarian stock, who had updated their internal management system to take maximum advantage of technological resources and made a firm commitment to national and international cooperation. The challenges facing these librarians nowadays involve preserving centuries-old books and preventing historic libraries from falling into decay whilst not losing the unique characteristics of these venerable and traditional institutions. In an attempt to combine preservation with access, historic libraries are now seeking out new users and offering greater access to works which, until recently, lay behind closed doors. This paper explores the current situation of historic libraries within a university environment and the changes they have experienced in recent years, as well as the role reserved for them in the near future.

\section{Los orígenes de la renovación}

Al menos en España, las bibliotecas históricas con manuscritos e impresos antiguos fueron las grandes olvidadas durante el intenso desarrollo que experimentaron las bibliotecas universitarias en la segunda mitad de la década de los 80 y parte de los 90.

La prioridad por entonces era conseguir que las Universidades aceptaran el concepto de unidad, es decir, la idea de que todas las bibliotecas existentes en una Universidad formaban en realidad una única biblioteca universitaria. Ahora es algo incuestionable, pero no lo era en los años 80 , cuando las universidades se habían llenado de puntos bibliotecarios en cátedras, departamentos y centros, sin suficiente relación entre ellos y sin personal especialmente preparado.

Afortunadamente, a mediados de los 80, tras la Ley de Reforma Universitaria, las universidades redactaron nuevos Estatutos, que en la mayor parte de los casos incluyeron una definición de Biblioteca Universitaria, así, en singular y en mayúscula, como un único servicio universitario de apoyo a la docencia y a la investigación.

Gracias a ello se inició un proceso, ahora imparable, 
- De coordinación funcional, e incluso de unificación física, de bibliotecas que habían ido surgiendo en años anteriores.

- De centralización de servicios bibliotecarios, como adquisiciones o préstamo interbibliotecario.

- Y, por supuesto, del comienzo de la implantación de sistemas automatizados e integrados de gestión bibliotecaria.

También comenzó a finales de los 80 y principios de los 90 el movimiento de cooperación entre bibliotecas universitarias. En España este movimiento cristalizó a nivel nacional con la creación de REBIUN (la red de bibliotecas universitarias españolas, que reúne actualmente a todas las universidades, 50 públicas, 26 privadas más el Consejo Superior de Investigaciones Científicas); y posteriormente, a nivel autonómico, con la creación de otras redes o consorcios, como BUCLE para las universidades públicas de Castilla y León - la comunidad autónoma en la que se encuentra Salamanca -, BUGALICIA para Galicia o MADROÑO para Madrid.

Con las redes cooperativas se han conseguido catálogos colectivos, acuerdos de préstamo interbibliotecario, adquisiciones centralizadas de publicaciones periódicas y recursos electrónicos, e incluso estudios estadísticos que han dado lugar a rankings bibliotecarios y evaluaciones de calidad.

Se trataba de modernizar las bibliotecas de las universidades y los primeros pasos estaban enfocados fundamentalmente hacia servicios y usuarios de fondos modernos.

\section{¿Qué ocurría, mientras tanto, con las colecciones históricas?}

Por supuesto, las instituciones contabilizaban los fondos antiguos que poseían. Y algunas reconocían abiertamente la importancia del fondo antiguo, si la colección era especialmente valiosa o si la biblioteca que los contenía, como en Salamanca o Coímbra, tenía interés artístico y podía presentarse como símbolo de la antigüedad de la institución.

Pero a veces los fondos antiguos eran más un problema que otra cosa, ya que, con algunas excepciones, se trataba de colecciones poco 
conocidas, con unos usuarios muy particulares y en general escasos, muchas veces con más repercusión fuera de la universidad que dentro de ella. Además, el fondo antiguo requería normativa y catalogación propia, especiales cuidados e inversiones en microfilmación o en restauración, lo cual no encajaba mucho dentro de las nuevas tendencias de servicios bibliotecarios plenamente coordinados, tecnológicos, abiertos y ágiles.

En las universidades clásicas españolas, es decir, las creadas con anterioridad al siglo XX, las colecciones de fondo antiguo se encuentran normalmente reunidas en las bibliotecas denominadas "generales", que suelen coincidir con las bibliotecas más antiguas de cada Universidad. Muchas eran consideradas como cabeceras de un sistema bibliotecario poco homogéneo, teóricas coordinadoras entre puntos bibliotecarios que habían ido surgiendo sin suficiente planificación. Pero durante los años 80-90, estas bibliotecas generales fueron perdiendo su carácter coordinador, en beneficio de "servicios centrales" de nueva creación; o bien se transformaron ellas mismas en estos "servicios centrales", invirtiendo sus esfuerzos y recursos económicos en lograr objetivos comunes de modernización.

Todo ello, vuelvo a decir, enfocado fundamentalmente a los fondos modernos.

Debido a este proceso que acabo de relatar, durante esos años las bibliotecas con fondos antiguos quedaron bastante fosilizadas.

Así, en las universidades se constituyeron de forma independiente dos tipos de bibliotecas: las que merecían recursos económicos, personal y dedicación, con fondos modernos y actualizados; y las que podían servir, fundamentalmente, de símbolo de la antigüedad de la institución.

Las bibliotecas históricas o secciones de fondo antiguo continuaron realizando sus trabajos habituales:

- Catalogación manual.

- Archivo de seguridad en microfilm.

- Atención directa a los usuarios.

- Difusión limitada y muy especializada. 
En casos como el de Salamanca aumentaron las visitas a la Biblioteca Antigua sin que, en realidad, nadie la viera como una biblioteca viva y en funcionamiento, con sus propias necesidades de renovación, sino como una especie de foto fija de la brillante historia de la Universidad de Salamanca.

En resumen, las bibliotecas con fondos históricos eran centros respetados, imprescindibles para un número pequeño de investigadores, pero podríamos decir que tenían poco peso institucional.

\section{La situación actual}

Este panorama ha cambiado bastante desde finales de los 90 y las bibliotecas históricas o secciones de fondo antiguo de las universidades siguen siendo bibliotecas especiales, pero en absoluto ancladas en el pasado ni ajenas a los criterios que influyen en la evaluación de calidad de las universidades.

\section{¿Qué acontecimientos, qué razones han propiciado este cambio?}

En el caso español, las transformaciones comenzaron con un nuevo marco legal y un cambio en la sensibilidad institucional y social.

1. Con la promulgación de la Ley de patrimonio histórico español de 1986, la legislación se ocupaba por primera vez de la definición y protección del patrimonio bibliográfico, como patrimonio individualizado. Uno de los artículos de esta Ley se ocupa específicamente de la confección del Catálogo Colectivo de Patrimonio Bibliográfico de España, que años después empezó a estar accesible en Internet. Hoy este Catálogo Colectivo está muy adelantado y podemos considerarlo como la herramienta más básica, la primera, el primer instrumento que dio visibilidad a nuestro fondo antiguo.

2. Otra circunstancia que ha favorecido al patrimonio bibliográfico es el interés institucional y social por el patrimonio histórico-artístico 
en general. Esta preocupación nació y se consolidó, por supuesto, en años de abundancia económica: se crearon asociaciones de amigos del patrimonio, se organizaron grandes exposiciones, surgieron mecenas para abordar rehabilitaciones, etc. No fueron los libros, desde luego, los principales destinatarios de este interés por el patrimonio histórico, pero tampoco fueron marginados; y, paradójicamente, algunas desgraciados episodios de robos y expolios, que dejaban en entredicho la conservación y control sobre los libros antiguos, han ayudado a la "rehabilitación social" del patrimonio bibliográfico.

3. En este contexto, las instituciones, incluyendo las universidades, empezaron a asumir que su Patrimonio Bibliográfico es uno de los valores estratégicos más relevantes que tienen y que su posesión les exige una responsabilidad social de conservación y difusión, con dimensión nacional e internacional.

Paralelamente, desde una perspectiva puramente bibliotecaria,

4. Los estudios anglosajones sobre descripción de fondos antiguos propiciaron la adopción en España de las reglas de catalogación internacionales y la adaptación para fondo antiguo de las etiquetas MARC 21. Así, desde mediados de los 90, los catálogos colectivos en línea que reúnen los fondos de cada Universidad, empezaron a incluir manuscritos o incunables al mismo tiempo que monografías o revistas del siglo XXI. Creo que esto, más que ninguna otra cosa, favoreció que los propios bibliotecarios tomaran conciencia de que las bibliotecas históricas o secciones de fondo antiguo, a pesar de sus particularidades descriptivas, eran una parte efectiva del sistema bibliotecario de las universidades.

5. Años después, ha llegado la digitalización al fondo antiguo y nos hemos unido a ella con pasión. La irrupción de Google en el libro antiguo o la creación de Bibliotecas digitales, como la gran EUROPEANA, han empujado a las instituciones a crear Repositorios propios, Bibliotecas digitales o Proyectos de digitalización orientados ya exclusivamente a libros y prensa antiguos.

6. Por otro lado, se creó un Grupo de Trabajo de Patrimonio Bibliográfico dentro de REBIUN, la red de Bibliotecas universitarias españolas. Las bibliotecas históricas entraron así en el mundo de la coordinación 
bibliotecaria, ya muy activa en las bibliotecas con fondos modernos. El Grupo es muy dinámico y ha organizado exposiciones comunes, ha dictado directrices de actuación y gestión y ha publicado diversos estudios sobre el patrimonio universitario en España.

\section{Así pues, ¿Cómo están hoy las bibliotecas con fondos históricos?}

En español tenemos un dicho recurrente, "Renovarse o morir", cuyo origen algunos ven en la supuesta frase de Miguel de Unamuno "Para progresar es necesario renovarse".

Pero no menos conocida es esa cita del príncipe di Lampedusa en su novela Il Gattopardo, "Se vogliamo che tutto rimanga come è, bisogna che tutto cambi" o "Si queremos que todo siga como está, necesitamos que todo cambie".

En nuestra búsqueda permanente de equilibrio entre conservación y difusión, las bibliotecas históricas con fondo antiguo queremos todo: rejuvenecer para no tener la apariencia de instituciones decadentes; pero también conservar intacto nuestro patrimonio y nuestra personalidad.

Seguimos siendo bibliotecas de reserva, con una personalidad propia, cuya función principal es la conservación, siempre en equilibrio con la investigación y con la difusión. Pero a medida que hemos decidido "renovarnos o morir", estos tres pilares tradicionales se han vuelto casi irreconocibles en muy pocos años:

- Los métodos de conservación se han ampliado.

- La investigación es cada vez menos presencial.

- Y la difusión se ha multiplicado.

Esta segunda juventud de nuestras bibliotecas y libros antiguos ha venido fundamentalmente de la mano de las nuevas tecnologías, aplicadas a diversos aspectos de la gestión bibliotecaria:

En cuanto a Conservación y Preservación, se han adoptado avances tecnológicos fundamentales, relacionados con los sistemas de detección de robos e incendios o el control de constantes ambientales, pero sobre todo es preciso citar la formación de archivos de seguridad digitales. 
En la biblioteca de Salamanca se mantiene aún la microfilmación, no por romanticismo, sino por la seguridad de conservación y lectura de la fotografía analógica. Pero las bondades de un archivo de seguridad digital, proceda de digitalización directa en color o de digitalización de los microfilmes, son innegables y no creo que sea necesario ahora analizarlas.

No obstante, con el archivo digital surgen al menos dos nuevos retos o dos nuevas preocupaciones, impensables hasta ahora:

- Necesidad de almacenamiento en servidores con gran capacidad.

- Duda sobre la vigencia de las imágenes a medida que se actualizan los nuevos equipos.

Respecto a la Investigación, nuestros usuarios han dejado de ser mayoritariamente presenciales. Actualmente el número de usuarios a distancia que solicita información o copias por correo electrónico, triplica al número de usuarios presenciales. Este abismo es aún mayor si pensamos en los usuarios desconocidos que consultan o se descargan fondos a través de bibliotecas digitales o del Repositorio Institucional.

Se ha establecido, por tanto, un nuevo tipo de relación con los usuarios: ya no es solamente un tipo de usuario conocido, de trato directo o que solicitaba por carta una información meticulosa. Ahora también hay un usuario circunstancial a quien se le puede enviar rápidamente una información muy puntual; un usuario que solo se pone en contacto para solicitar copias de calidad superior a las que están a libre acceso; e incluso un usuario totalmente anónimo, un número en la estadística de uso del Repositorio.

También la Difusión de los fondos de las Bibliotecas se ha multiplicado en los últimos años y, sobre todo, se trata de unos modelos de difusión que llegan a muchos más tipos de personas, no solo a las especializadas o interesadas en determinados libros.

Exposiciones virtuales que permiten enlaces a los ejemplares expuestos, con posibilidad de descarga de imágenes y textos; Publicaciones digitales y blogs especializados en fondo antiguo; o Participación de las bibliotecas en las redes sociales, son algunos de los medios de difusión que actualmente se están utilizando. 
Pero me voy a centrar en tres instrumentos básicos:

1. Por un lado, los subcatálogos de fondo antiguo dentro del catálogo colectivo general de la biblioteca universitaria que permiten recuperar la información por más puntos de acceso de los que estamos acostumbrados, y que además pueden llevar un link al texto completo de ese ejemplar o de otro que se encuentre en la Red y que pertenezca a otra biblioteca.

2. Además, la descripción de nuestras obras antiguas, nuestro propio catálogo, está ahora consultable desde numerosos catálogos colectivos y recolectores nacionales e internacionales (CCPB, REBIUN, WORLDCATOCLC, etc.). Esta internacionalización de nuestros catálogos facilita enormemente la labor no solo de los investigadores que buscan ejemplares, sino también la labor de los bibliotecarios, a la hora de realizar una descripción, completar datos o comprobar la rareza de una edición.

3. Finalmente y como complemento de los catálogos meramente descriptivos, todas las bibliotecas están inmersas en Proyectos de digitalización de texto completo, propios o en colaboración con otras instituciones, y en la integración de estos textos completos en los Repositorios institucionales, con acceso desde el propio catálogo o desde bibliotecas digitales nacionales e internacionales, como HISPANA o EUROPEANA.

Sin duda este es el modo de difusión más completo a que puede aspirar una biblioteca y por ello todos nos hemos zambullido alegremente en proyectos, costosos en personal y tecnología, que hasta hace unos años eran relativamente fáciles de financiar. Pero la avalancha de proyectos ha generado duplicidad de ejemplares en la Red, de modo que, últimamente, los grandes repositorios como EUROPEANA o GOOGLE no aceptan fácilmente ejemplares duplicados para difundirlos desde sus plataformas.

\section{Futuro inmediato}

En definitiva, nunca como hasta ahora las Bibliotecas Históricas habían podido dar a conocer su fondo ni habían trascendido tanto sus muros. Acabamos de vivir unos años muy brillantes, con algunas sombras pero con muchas luces, que han sido bien aprovechados. 
Pero el inmediato futuro es una incógnita:

- Estamos viendo la decadencia de las grandes exposiciones, que ayudaron durante años a la divulgación del patrimonio bibliográfico.

- Hay disminución de proyectos de investigación de humanidades.

- Detectamos en los últimos tiempos menos estudiantes orientados a trabajar con fondos antiguos, que entiendan paleografía o latín...

Mantener el estatus de modernidad alcanzado en estos últimos años, sin contar con los apoyos económicos a los que nos habíamos acostumbrado, nos va a costar nuevos esfuerzos de adaptación.

Tocará una vez más renovarse o morir, probablemente en las siguientes líneas:

\section{Internamente,}

1. Ideando nuevos métodos de captación de patrocinadores para la conservación y preservación de libros o infraestructuras.

2. Saliendo a la búsqueda de nuevos usuarios, fomentando nuevas líneas de investigación, basadas, por ejemplo, en las procedencias de los libros o en los grabados, y promoviendo seminarios con estudiantes.

\section{En cooperación,}

3. Incrementando nuestra participación en proyectos cooperativos e intercambios bibliotecarios.

4. Estudiar vías de perfeccionamiento de la digitalización, probablemente en la mejora de los OCR para impresos anteriores al siglo XIX.

Como conclusión, quiero resaltar que, gracias a los esfuerzos de renovación de los últimos años y a pesar de los difíciles momentos económicos o de indefinición bibliotecaria que estamos atravesando, nuestros libros están más jóvenes que nunca y las bibliotecas históricas gozan de buena salud. 
No sabemos qué futuro le espera al libro en papel.

No sabemos cómo sobrevivirán las librerías al libro electrónico y a la relación directa entre el editor o distribuidor y el usuario final, sea éste un lector o una biblioteca.

Tampoco sabemos aún adónde nos llevará la alfabetización informacional o la sustitución en las universidades de las bibliotecas tradicionales por los modernos CRAIS (Centros de Recursos para el Aprendizaje y la Investigación).

Pero con más o menos usuarios, con o sin recursos, es seguro que las bibliotecas históricas van a permanecer donde están. Aunque todo el patrimonio llegara a estar disponible en la Red, nuestra principal función de conservación patrimonial garantizará siempre la existencia de una biblioteca.

Ya ven. Todo (o casi todo) cambió, pero todo sigue igual.

En un delicioso libro titulado $C$ El pequeño libro que aún no tenía nombre, su autor, José Antonio Millán, nos presenta a un pequeño libro que aún no está escrito, que debe crecer y encontrar su lugar en el mundo. Su padre es un elegante volumen de derecho civil y su madre una moderna y dinámica revista científica, que todas las semanas cambia de portada. Su abuelo es un aristocrático ejemplar de arte de la guerra y su abuela un delicado manual de educación y buenas maneras. Cuando C se pierde por barrios marginales y queda horrorizado ante la visión de libros fotocopiados y libros atacados por lepismas, es rescatado por un código de la circulación. Toda la novela es así y fue escrita en 1995, hace 20 años. De haberla escrito ahora, no sé si el autor habría hecho convivir a $\mathrm{C}$ con libros digitales, descritos como adolescentes enganchados a dispositivos electrónicos. Probablemente la madre se habría convertido en una revista electrónica, más viajera y colorida aún que antes; y no sé qué sería de $\mathrm{C}$, conviviendo con su versión electrónica.

Pero es seguro que sus abuelos, esos exquisitos volúmenes antiguos, continuarán impasibles y bien cuidados en una de nuestras bibliotecas históricas. 
José Augusto Cardoso Bernardes é Professor da Faculdade de Letras da Universidade de Coimbra e Diretor da Biblioteca Geral da Universidade

Ana Maria Eva Miguéis é coordenadora do Serviço Integrado das Bibliotecas da Universidade de Coimbra

Carla Ferreira é bibliotecária nos Serviços de Biblioteca e Documentação da Faculdade de Letras da Universidade de Coimbra. 


\section{Série Documentos}

Imprensa da Universidade de Coimbra

Coimbra University Press

2015

C •

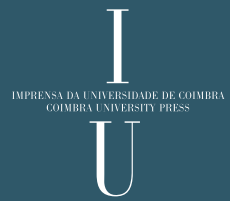

